\title{
Individualization as Depersonalization: Minority Studies and Political Anthropology
}

\section{Arpad Szakolczai, Agnes Horvath \& Attila Z. Papp}

To cite this article: Arpad Szakolczai, Agnes Horvath \& Attila Z. Papp (2017) Individualization as Depersonalization: Minority Studies and Political Anthropology, Nationalism and Ethnic Politics, 23:1, 1-17, DOI: $10.1080 / 13537113.2017 .1273653$

To link to this article: http://dx.doi.org/10.1080/13537113.2017.1273653

\section{曲 Published online: 20 Jan 2017.}

Submit your article to this journal $[\pi$

Q View related articles $\sqsubset$

View Crossmark data $\nearrow$ 


\title{
Individualization as Depersonalization: Minority Studies and Political Anthropology
}

\author{
ARPAD SZAKOLCZAI and AGNES HORVATH \\ University College Cork
}

ATTILA Z. PAPP

Hungarian Academy of Sciences

\begin{abstract}
This article offers an introduction to the special issue. It presents the arguments why a political anthropological perspective can be particularly belpful to understand the connected political and cultural challenges and opportunities posed by the situation of ethnic and religious minorities. The article concisely introduces the major anthropological concepts used, including liminality, trickster, imitation, and schismogenesis; concepts that are used together with approaches of historical sociology and genealogy, especially concerning the rise and fall of empires, and their lasting impact. The suggested conceptual framework is particularly belpful for understanding how marginal places can become liminal, appearing suddenly at the center of political attention. The article also shows the manner in which minority existence can problematize the depersonalizing tendencies of modern globalization.
\end{abstract}

There are, at least, five good reasons why minorities —ethnic, linguistic, or religious - are a worthwhile, even important, area of study for the political and social sciences. To begin with, and most simply, because they simply exist, even though often they are ignored, or belittled, following the seemingly self-evident logic of identifying a nation-state with a single group. Second, such groups offer color and variety; it is good to know about them, as they help to stay aware about the multiplicity of life and culture in a world increasingly threatened by global uniformity. Third, and even more importantly, beyond "exotic" charm, such communities offer a reality check

Address correspondence to Arpad Szakolczai, Professor of Sociology, Safari Building, University College Cork, O'Donovan's Road, Cork T12 YN60, Ireland. E-mail: arpad.szakolczai@gmail.com 
against these processes of mechanization and uniformization, moving beyond the idea of taking the "modern West" as an unsurpassable horizon. Fourth, beyond merely surviving, in contrast to the dominant majority of their respective countries, they perform, or could perform, an important role of mediation. Fifth and perhaps most importantly, the existence of such minorities both render evident and help to literally resist the arguably most central and most pernicious aspects of modern globalization, which is not simply standardization, mechanization, bureaucratization, commodification, or commercialization but also depersonalization. The central aim is to analyze this phenomenon with the help of concepts developed in political anthropology.

This short introduction will offer an overview of political anthropology, ${ }^{1}$ with a focus on its features that might have particular relevance for minority studies. The central aim of this special issue is to suggest a theoretical framework for analyzing the situation and role of minorities, with a focus on deeply divided societies, and to apply it for some European countries where significant ethnic minorities are present, and where there is a strong religion-based conflict dividing the society. Anthropological concepts central for this theoretical framework include liminality, imitation, trickster, and schismogenesis; concepts that are little used, especially together, outside specialized anthropological studies but that have particular relevance for the study of sociopolitical conflicts in the modern world. In particular, using the conceptual pair "marginality/liminality," this special issue investigates how such situations emerge in peripheral areas that are also in between major cultural, political, and civilizational centers and in the outskirts of Europe, and how such "marginal" places can gain a liminal position in mediating between societies and cultures but also in becoming permanent sources of conflict. Such at once marginal and liminal areas, studied in some details in the articles that follow, include Hungary, Romania, Moldavia, Lithuania, Bosnia, Cyprus, and Northern Ireland.

The reason why we offer a set of anthropological concepts that were so far rarely used in the study of contemporary politics is dual, justifying the undertaking from two angles. On the one hand, living as member of a minority - ethnic, linguistic, or religious — is a matter of everyday living and an often quite difficult, conflictual one. Studies of such situations easily require the standard anthropological or ethnographic tools of extended fieldwork and participatory observation. However, on the other hand, the very existence of such minorities as minorities, often quite isolated and embittered minorities, is a consequence of long-term historical changes, mostly due to the building and collapse of empires. This implies, at a first step, the rise of a conquering empire, and its subjugation of various people, often involving forced population movements and then a protracted existence under such an empire that often can extend for long centuries, under which various efforts are made by central authorities to integrate and assimilate 
the conquered; eventually, the necessary collapse of an empire might lead to situations of nation-state-building with its own homogenizing efforts as a legacy. This also implies that the perspective of political anthropology makes use of comparative historical sociology, especially the genealogical perspective, as pioneered by Nietzsche and developed further by Max Weber, Eric Voegelin, and Michel Foucault.

The paradoxicality of such a situation is not always understood in contemporary political analysis. The reason is that the central concepts of modern social and political theorizing are closely connected to the specific answer given to the concrete political and religious problems that emerged in Europe after the collapse of the Byzantine Empire and thus the medieval world order, but theorists fail to see the contingency of their own answers, starting with the ideas of Machiavelli and More, and especially Hobbes. The significance of anthropological approaches and concepts is thus not simply that they stay close to the everyday reality of minorities but that such concepts can escape the limits of taken-for-granted modern concepts, closely tied to the (absolutist) state.

The central paradox of the postimperial situation is that the mess generated by empire-building, this "concupiscential conquest" (Voegelin), always driven by an inner void, is not easy to clear away. ${ }^{2}$ Populations that became mixed, as forced to live together for long decades or centuries, cannot be easily separated. The oldest example for the absurdity of such efforts takes us back to the Book of Ezra in the Old Testament, a first case for ethnic cleansing, where the high priests, back - eventually — from the Babylonian captivity, stood judgment over their people, expulsing those with foreign wives. In such a context, enforced homogenization by the "liberated" people can be even more oppressive and violent than imperial policies; while the seemingly "liberal" and "democratic" solution of tying down people, in a setting where intermarriage was the fact of life since generations, to a single and unambiguous ethnic identity can be just as oppressive and even ludicrous.

Beyond these problems, we would like to single out for attention one particularly problematic element of the taken-for-granted framework of modern European thought, associated with the legal, administrative, bureaucratic, processual, and policy-obsessed aspects of state formation. This is the increased depersonalization associated with the rise of the modern world — not exclusive to politics, but particularly pronounced there, and rendered visible by various minorities.

\section{DEPERSONALIZATION VERSUS THE MINORITY PERSON}

The problem of the depersonalizing effects of the modern state and modern capitalism was at the heart of Max Weber's work. This aspect, which cannot 
be reduced to the more specific diagnoses of "bureaucratization" or "rationalization," has recently been emphasized by Wilhelm Hennis, a political scientist who argued that Max Weber's central theme of work was concerned with the tension between personality and the "life orders" under contemporary conditions. ${ }^{3}$ It is due to perceiving such depersonalizing effects that Weber was intrigued by Nietzsche's diagnosis of modern nihilism, animating some of his last conclusive words, like the January 1919 lecture Politics as a Vocation, containing the passage "Not summer's bloom lies ahead of us, but rather a polar night of icy darkness and hardness ... [w] here there is nothing," ${ }^{4}$ giving a negative response to the still open ending of the Protestant Ethic, envisioning that the "last men" of this civilizational development could be " specialists without spirit, sensualists without heart: this nullity imagines that it has attained a level of civilization never before achieved," ${ }^{5}$ or his last completed lecture course on General Economic History in the 1919-20 winter term, ending with evoking a new "Iron Age."6

Such diagnoses are notable not simply due to their pessimism but by capturing a type of development where depersonalization is continually increasing, paradoxically together with rising individualism and fake personalization. This is because the term "individual" has two radically different shades of meaning. On the one hand, the "individual" stands for the concrete, single human being, implying the myriad ties and connections one carries within his or her person - family, friends, and colleagues or religious, ethnic, linguistic, and professional. On the other, in both modern economics and the "public sphere," the individual is a single, atomized entity, alchemically separated from every possible tie, left with nothing else but one's "interests" (a word itself capturing in-between-ness but here transmogrified into something objectified "inside" the individual) and reasoning power; thus, a conceptualization perfectly compatible with the most extreme depersonalization. Depersonalization divides entities, where each divided entity must construct an "identity" that would then be "recognized" by the others; quite close to the analogy of the way the nation-states "recognize" each other, in the Westphalian system. However, the multiplication of recognized identities does not necessarily mean an undisturbed personality but quite the opposite. Over time the negative aspects of depersonalization and the deep-seated anxieties it produces are also becoming more and more evident and dominant, leading to increasing warfare and conflicts, not only in the past but the present as well.

Thus, beyond terms like "ambivalence" or even "tension," we need concepts that can capture together both sides of modernity, depersonalization, and individualization and the increasing gap and tension between the "person" (the authentic, concrete self) and the "individual" (a bundle of sensation that tries to maximize pleasure and minimize pain, "constructing" one's identity). There is an anthropologically derived term that does this feat, and this is "bipolarity," developed by Gregory Bateson on the basis of his earlier 
concept of "schismogenesis." Here, we immediately enter at the heart of the history of the long past centuries, the schismatic history of the civilization to which we belong. Such schisms include the Great Schism between eastern and western Christianity, the Reformation and the subsequent further schisms within western Christianity, the schisms between nations and social classes, resulting in the social and national problems tearing apart the continent and leading to World War I, the East-West schism of the Cold War, and, most recently, the waves of mass migrations that became a new state of normalcy in the contemporary world.

By pursuing Weber's diagnosis one of the central anthropological concepts has already been introduced. In the next sections, a more systematic introduction will be offered about the central anthropological concepts on which this special issue relies.

\section{POLITICAL ANTHROPOLOGY}

The idea that social theory needs not only a historical but also an anthropological dimension goes back to the classics. Weber tried to incorporate anthropological studies into his approach, while Emile Durkheim, his contemporary, directly championed an anthropological perspective to sociology. However, the most relevant anthropological ideas do not derive from Durkheimian sociology but rather from its main dissenters. These include Arnold van Gennep, who in his Rites de passage introduced the idea "liminality," Gabriel Tarde, who suggested the centrality of the term "imitation," thus redirecting sociology to Platonic foundation, close to the ideas of Alexis de Tocqueville, and even Marcel Mauss, Durkheim's nephew and designated heir, whose ideas about the importance of praying (theme of his unfinished dissertation) and gift relations directly challenged the Durkheimian focus on rituals of sacrifice, or Lucien Lévy-Bruhl and his focus of participation, away from Durkheim's neo-Kantian concept “collective representations." Further ideas that were for a long time marginal even for anthropology but now are increasingly becoming central, through political anthropology, for social and political analysis include the "trickster" and "schismogenesis."

Within the scope and limits of this writing, it is not possible to introduce these various ideas in detail. We can only illustrate how they all hang together. This offers a novel way to analyze the genesis of the modern world in depersonalization, through a series of concepts that were developed by anthropologists in their studies of nonmodern and non-Western societies. It thus overcomes the central problem of self-referentiality in social theory: analyzing the rise and dynamics of modern societies in emptying entities by concepts developed from within these same societies.

To start with, liminality helps to capture and analyze, with a degree of analytical rigor, what happens under ephemeral and fluid conditions of 
transition and uncertainty. ${ }^{8}$ Rites of passage are those rituals that assist the transition of a group of individuals, or an entire community, through major points of passage in life: birth and death, adulthood and marriage, illness or other types of crises, or simply the rhythm of seasons. They have three phases: rites of separation; the rite itself, a performance or testing; and the rites of reaggregation. The main liminal moment is the middle stage, but each of the three phases is liminal in its own way.

While the concept was developed through studying rituals actually staged in various small-scale populations in the world, its relevance for the modern world, or for understanding the dynamics of historical events, is evident. A social, political, or economic crisis can be analyzed as a realworld large-scale moment of transition in which the taken-for-granted, stable structures of social and human life are suddenly suspended, and there is an intense search for a solution. This is the type of situation that was at the center of Max Weber's political sociology, the problem of an "outof-ordinary" (ausserallägliche) situation, for which he developed the term "charisma." For Weber, out-of-ordinary situations cannot be solved by ordinary, traditional-customary, or rational-legalistic means, because the stability that is the basis of such solutions was undermined. They require the appearance of a special kind of person who has "charisma" or a transcendental power for transformation. Weber clearly intimated that Europe after WWI required such leaders, but there are never guarantees that such persons would arrive.

Political sociologists and political scientists over the past century meticulously applied the Weberian terminology to the actual "out-of-ordinary" political leaders of the past century, without paying attention to the question whether these leaders had genuine charismatic qualities. This is where the anthropological concept "trickster," invented by Paul Radin, is particularly helpful. ${ }^{9}$ Tricksters abound in folktales, mythologies, and ethnographic accounts in most cultures of the planet. The trickster is a peculiar in-between figure, specialized in soul fetching or depersonalization. It is the eternal outsider, not member of any community, not participating, thus not having emotional ties, but for the very same reason able to perceive how it is possible to direct others through their emotions, or even outright stimulate or produce emotions in others, literally playing with human emotions as if on a musical instrument. They are lonely wanderers, moving from one place to another, always in search of conditions where they could suddenly jump from the periphery into the center, making themselves useful, even indispensable, convincing people to accept the changes in themselves. Thus, tricksters are living paradoxes, both outcasts and culture heroes, in many cultures even considered as second founders of the world. The trickster is a central conceptual tool complementing Weber's "charisma" in capturing a type of political leader that is outside both the realm of tradition and legal 
rationality. The conditions that favor their rise are situations of distress or crisis, where stabilities are dissolved, emotions become high, and people look for somebody who could guide them out of disorder.

In order to understand the trickster mode of operation, we need to review in some detail, what happens in uncertain and anguishing periods of transition. As the taken-for-granted order of things has become suspended, the form of conduct that were previously followed could no longer offer guidance. There is an intense search for new solutions with the mind being particularly excited. However, this coincides with emotional involvement, making the work of thinking difficult. In great distress, individuals look for each other in search of a solution or model to follow and, thus, can easily be induced to follow a course of action that otherwise they would never take, characteristic of crowd behavior, especially in panic, analyzed by Gustave le Bon, a contemporary of Nietzsche and a major source of the thinking of Durkheim, Tarde, Pareto, and Freud — and also, through Sorel, of Mussolini, Hitler, and Lenin. Thus, liminal situations jointly incite both reasoning and emotions.

Under such conditions imitative processes can easily spiral out of control, characteristic of violent mob action, even scapegoating, analyzed so well by René Girard or Gabriel Tarde. However, the situation is different if there are some people within the community who manage to use their sense and offer a solution. These are, in a Weberian terminology, the genuinely charismatic persons, who rise up to the opportunity and lead the community out of the crisis. The problem is that the same situations also favor tricksters, whose mind remains clear, as they are not emotionally involved in the community and do not have an interest in finding a solution. Quite on the contrary: As a trickster can only gain attention in a crisis, its only interest is in perpetuating situations of crisis. It can capture attention with slogans that seem to offer a way out - people in a state of distress are not terribly good in making distinctions, their sense of judgment being undermined but that instead only spirals further the very forces that generated the crisis.

There can be two basic outcomes of such a situation, which can also be combined. If a temporary situation of crisis is perpetuated, we are faced with a paradoxical condition of permanent liminality ${ }^{10}$ that is based on depersonalization and further promotes the same transformation from a person into a nonentity (Weber's "nullity"). The second main outcome is schismogenesis, ${ }^{11}$ which means that a temporary breech or fracture in the social fabric, instead of being healed, is rather extended and aggravated until it becomes a permanent condition. The trickster logic here implies that instead of finding a way to close the gap and to resolve the conflict, the diverging positions are rather getting more and more distant from each other, until the previous unity is replaced by two sets of strongly different identities. Central for Bateson's concept is the modeling of the process by which the previous positions of identity are replaced by the two new identities, based both on 
the redefinition of the "self" and of the "other" and the progressive taking into account in the definition of the self how the other "labeled" this self.

The unfolding of schismatic processes is not a once-for-all event but rather, following the logic of "Bateson's Rule," one fracture can lead to another. Schisms can multiply with a new identity splitting into further halves. The European Reformation of the 16th century offers a perfect example, with fragmenting only stopped by all partners recognizing the others so as not to allow further destructive splitting, culminating in the establishment of the official churches. A similar example is offered by the socialist movements of the past centuries.

\section{THE MINORITY PERSON}

Without romantically overvaluing the challenges inherent in a minority existence, the anthropological concepts presented above offer a suitable framework for interpreting the particular position of members of ethnic or religious minorities.

According to Weber, the dynamic relations between ethnic groups can be described as a set of attractions and repulsions, while the groups themselves possess moral customs that can build communities. ${ }^{12}$ Some authors place the emphasis on the boundaries between ethnic groups, ${ }^{13}$ while others interpret ethnicity as a framework to perceive social differences. ${ }^{14}$ There is consensus that the interpretation of national minorities must be situated with the relationship between the nationalizing state and the kin-state. ${ }^{15}$ In this context, ethnicity or ethnic identity emerges through the interaction that is taking place between groups: Ethnicity "exists between and not within groups [emphasis in original]."16

The presence of minorities, or citizens who share a different culture or language, presents both an opportunity and a threat for the majority that usually possesses political hegemony. The assessment of minorities usually depends on the ruling political perspective: If a modern nation-state wants to demonstrate its own pluralism, it uses all political and legal means to demonstrate the existence and thriving of minority groups - especially outside its own borders-in order to receive recognition from other nationstates or supranational organization. Here, however, immediately a trickster aspect appears, through an internal contradiction, as a nation-state necessarily means national homogenization and, thus, strives for homogeneity. Thus, minorities regard the occasional tolerance of the local nation-state, just as the special favors offered by the distant kin-state, with due skepticism.

The moments and consequences of the collapses of empires are thus always different in the memory and interpretation of the "winners" and the "losers." The "winners," the majorities, found a home, while the minorities became losers, drifting into endless homelessness and entertaining new expectations while forced into an imposed political entity. Yet, at 
the same time, those with a shared culture and experiences generate close communities where the hope that the obstacles deployed against the free use of the proper language and culture would once be lifted. The daily life of a minority person is sometimes only latently, sometimes manifestly, penetrated by the dominant concern of preventing those actions of the majority that are supposedly oriented towards eliminating the very survival of the minorities.

The persons inside such (forced) communities, however, apart from the evident losses and deprivation, also received a chance ${ }^{17}$ : As one's very existence became defined in contrast to the majority, often conceived as an enemy, this gave the opportunity of living, inside the modern world, as member of a particularly closely knit and personalized community, reversing - at this concrete time and place - the dominant modern tendency of depersonalization. Thus, living as a member of a concrete community offers the chance of intimate inwardliness (bensóségesség; a term quite different from individualizing but also depersonalizing privacy and intimacy), recovering a genuine dialogue all but lost in modernity. The dialogue of minority persons thus is not conducted between atomized and universal individuals, rather between persons who belong to the same ethnocultural community. The permanentization of such a dialogue might lead to a kind of inbreeding but can be an instrument for offering a transition from homelessness to a home. The realization of the hope of independence might shift a minority person out of this personalized world; thus, after the collapse of the Habsburg Monarchy or the Soviet Union several previous minorities suddenly became majorities, thus founding a home, and as the "new victors" started to act in every manner according to the logic of the majority nation-state, even in confrontation with their own new minorities.

A minority person can choose between several life strategies: One can take upon oneself a mediating role between the various linguistic, ethnic, and political entities (different minorities or the various, neighboring nationstates), but one can also follow the policy of separation or even of some or other versions of ethnic resistance. Whatever strategy is chosen, the actions will be pervaded by some kind of hope and the public demonstration of this hope. In the first strategy, it is the idea-ideal of "eternal peace" or "tolerance" that transpires, while, in the second, a belief in autonomy of one kind or another (individual, institutional-cultural, or territorial). A minority person always lives in some kind of belief, hope, teleology, or in an eternal inbetween state and, thus, can easily be deluded, especially if someone evokes danger, crying wolf. And danger or threat is never far from the horizon of minority existence; a minority person, if only to heal or at least to sooth a trauma, needs to believe in a better world to come. So, a minority person must build on this paradoxical, as if structural metaxy-existence, ${ }^{18}$ on the bridging between present and future, good and evil, no-longer-majority and yet-still-minority, or only-minority and not-majority. 
The minority elite works on these same bridging, often accepting and even feeding those ideologies and hopes that could tilt the minority into a fulfilled future. This requires a certain imitation, the imitation of the elite behavior by minority members, which also offers an opportunity for various internal and external tricksters to appear. By internal tricksters, we mean those individuals or ideas that, already before adherence to a minority community, were connected in one way or another to the "saving" of the minorities; whereas, external tricksters are those potential saviors or ideas that attempt to "save" the presumed minority community subsequently and from the outside. Here, it is important, at least in a Central-Eastern European context, to emphasize the role of the "home country" (where the ethnic minority of one country constitutes the majority in another), where political actors, and not always for the right kind of reasons, come to emphasize the solution or "arrangement" of the minority problem or the "saving" of the minority persons considered as "authentic."

The relationship between kin-state politicians and the minority community can be characterized by mutual, calculative, mistrustful incomprehension, thus involving irresolvable contradictions. In order to understand the inherent trickster aspect of this relationship, we first need to realize that, no matter how such communities are unified, they still contain their own inner differentiation. While, due to their common goals, minority persons behave in a quite similar manner, they have certain segments, whether in a regional or social sense, which contain sociocultural essences that resonate better with the kin-state actors — or at least make them pretend so. ${ }^{19}$ Such an entangled relationship can be considered as a joint trick of the kin-state majority (or at least its political representatives) and the minority, against genuine pluralism, where some kind of mutual imitation is staged, in order to reach some kind of proclaimed authenticity.

Minority persons often act as if they were a majority, only demonstrating their minority being by this very feature. They identify themselves with a minority existence as if they were not at all like that: They politicize and act as if they were the majority, even bracketing their minority identity. This even applies to the more "authentic" minority persons, who - meeting somebody from the kin-state majority - can easily gain inspiration for forgetting their own minority identity. But how is this possible? It is based on two premises: On the one hand, the minority person is capable of using an ambivalent language, ${ }^{20}$ through which it can discursively appropriate the complex and manifold minority-majority relationship. On the other hand, a majority member of the kin-state by visiting the minority communities might leave for a time his own social existence, entering the personal world of minority communities that are perceived as authentic. This is an indication of the bipolarity of the modern world between individual and person.

In the minority community, the member of the kin-state is not "indigenous" but rather participates in an alien world where one knows the 
language and - to some extent - the culture. The perceived closeness of the minority people and the authenticity experienced actually strengthens a "trickster" identity in the kin-state person, who comes to believe that one can actually "save" the minorities through one's own means. The question is to what extent this benefits the minorities. Perhaps, by making them forget even more their minority existence, as the (external) kin-state trickster elevates them to such heights where only majority persons can accede. This thus offers one a certain experience of authenticity, which, however, is very different from the need for authenticity demanded by kin-state persons. Still, on the part of both sides such acts become means for a further depersonalization or an escape from one's own inner void. It remains to be seen to what extent they merely fall into each other's traps, and whether they will be capable of a genuine dialogue, of a similar living and interpreting of space and time. A minority person is not always dreaming about somebody saving him, thus the kin-state politician can easily lose one's charismatic aura, revealing his role as the savior of minorities as a mere mask. Thus, one can well imagine the relationship between minority and kinstate persons as one of a mutual and watchful glaring at each other from a distance.

The minority person himself, and any encounter with him have a liminal character. The emergence of such a mode of existence is always due to some kind of social schism, often of a multiple kind, and one's further, traumatic life is conduced on the borders between various worlds, often even encompassing the role of the victim or the scapegoat. In encounters between various minorities and majorities, however, not only the majority persons can redefine their own positions, even themselves, but even the minority persons. Such continuous, dynamic transitions can produce new and new minority identities, which the "majority" might try again and again to understand or - due to its desire to transcend itself by such identification -incorporate and thus abolish.

\section{THE MEANINGS OF MINORITY EXISTENCE}

It might seem strange that all the articles in this special issue deal with marginal areas of Europe; in fact, mostly of extremely marginal areas. While we cannot claim comprehensiveness, not even full representativity, this is by no means accidental. The problem of minority existence is indeed something characteristic of the margins of Europe, and not of its - broad - center.

Even further, practically all the areas discussed in the articles fell outside the area of the former Roman Empire. This is all the more strange as the question of empires, their rise and collapse, was extensively discussed in the articles, including — quite prominently - the Byzantine world or the Eastern Roman Empire. Yet, here again, the western core is out of the scope. 
The reason concerns the specific affinities between empire-building, nation-state-building, and homogenization. Empire-building is driven by an insatiable drive for conquest, the very insatiability fueled by an inner void and, thus, the loss of meaning. The more the empire is extended, the more it conquers and formally incorporates areas that it cannot properly integrate culturally. Thus, the inevitable collapse of any empire leaves behind itself, after the devastation, a void - the same void, as if multiplied, or involuted, to which its very existence was due.

The void was filled, after the collapse of the Western Roman Empire, by the emerging nations, where life was maintained and given meaning by the Christian Church. After the schism of the Reformation, this eventually led, after the treaty of Westphalia, to the emerging absolutist states. The revolutions transformed the absolutist states into unified nation-states, but - as Tocqueville realized so well - by no means altered the drive towards centralization and uniformity. Such developments, far from representing "progress" in an absolute and universal sense, rather implied the formation of an increasingly homogenized and standardized world in which the insatiable centralization of states and markets (meaning the stock markets, one of the most centralized institutions ever invented on the planet) could progress jointly with a similarly streamlined individualization.

For a series of reasons, this "progress" was blocked in the eastern part of Europe and its surroundings - mostly for the worse but, in some ways, perhaps also for the better. While within its core areas, Islam produced, with its own means, a similar kind of homogenization in the broad lands between the margins of western Christianity and Islam, areas in close contact with (if not outright under) the Eastern Roman Empire and thus, following Eastern Orthodoxy, ethnic and religious diversity survived. This happened because the successive eastern empires (Byzantine, Ottoman, Austrian - literally "Eastern" - and Russian/Soviet) failed in both counts where the West succeeded, in the full ambivalence of the term "success." In the West, after the relatively early collapse of the Roman Empire, a Christian civilizing process emerged, resulting in meaningful and coherent communities, guided by the three major estates (Church, aristocracy, cities). These entities, after the collapse of the unity of western Christianity, "succeeded" to build, both using and abusing the previous civilizing process, ever more homogenized and centralized states, becoming ready to accommodate the new idols of mass democracy and mass markets, while external, overseas colonial expansion offered ways to increase resources and exteriorize conflicts. In the East, continental imperial expansion remained the objective, which, however, repeatedly failed to produce integration. The result was the coexistence of weakly integrated centers and a surviving manifoldness of local communities, many of which contained strange mixtures of local, indigenous communities: survivals of failed imperial centralization and homogenization, and migrants brought in to fill the void left by withdrawing or collapsing empires. 
This is the context into which the various stages of western-driven "modernization" projects can be inserted. These projects are, since centuries and with very little learning from previous mistakes, a curious combination of pure extensions of the colonial mentality - exploit the region, just as the colonies, in the interests of the mother country; a taken for granted and self-assertive "civilizing mission," very different from the original goal of Christianization; and a desperate effort to clean up and contain the mess, once the instability of the region was threatening the core countries themselves. This implied, first, a conscious effort to maintain the empires (Austrian, Russian, even Soviet) in order to contain the indiscriminate "savages" of the "East"; then, after the collapse of these empires, an often even genuine and well-meant - effort to extend there the benefits of modern civilization without being aware, in the minimal degree, of the considerable human price involved in such a homogenizing and liquefying "civilizing" effort; thus, as an inevitable result, the increasingly mechanized responses offered by the irritated center that failed to perceive the limits of its own dogmatic Kantian rationality, thus only perpetuating and fixing fault lines in the margins. Given the utmost lack of knowledge, interest, and care by the center in local affairs, and an arrogant belief in the superiority of its own abstract, "rational," constructed institutions, such efforts - just as in the former overseas colonies - created potentially explosive situations, held together by the threat of force, while the enforced requirement of identification alongside rigid and absolutized lines time and again only tore up wounds, unmaking healing processes that at the local level emerged due to the natural effects of the passing time. Institution-tinkering does not offer any solution, only tries to freeze conflicts, without healing root causes, and often at a similarly high price that the fooled migrants of our days had to pay for their "agents." Genuine personalities and communities are not mere constructs, so "constructing" institutions only freezes, temporarily, the situation, instead of offering a stable, long-run solution; thus, in the remarkable expression of Jesenko Tešan, a perpetual peace treaty, modeled on the work of Kant, only generates a permanent, frozen war.

Such western, enlightened, and absolutizing dogmatism was complemented in the East by the particular virulence of a trickster logic that is bound to emerge and rise to dominance in marginal border zones where and when transitioriality becomes increasingly permanent. The achievements of the West, which were partly genuine but partly only outcomes of a merely quantitative growth of power, generated by social and human homogenization, a precondition of technological growth, as Heidegger, Mumford, or Borkenau perceived so well, had to be transmitted to the East; and such mediation, communication, commerce, transport, and traffic is a prime area for the trickster, captured particularly well in the figure of Hermes. Such tricksters might thrive in nation-building, being more "patriotic" than any locals, or might, on the contrary, bemoan the hopeless backwardness of their countrymen, forcing them to follow the tide of "progress," as they only 
know it better. Most importantly, they might shift with stunning speed from one position to the other.

Such marginal areas, which are also liminal due to their mediating or in-between character (between East and West, North and South, Catholicism and Protestantism, Roman and Orthodox Christianity, Christianity and Islam, etc.), are particularly prone for falling into a mimetic escalation, which provides a further breeding ground for trickster figures to emerge and thrive, preventing any return to normality, given that confusion is the condition of possibility for tricksters to gain and maintain power.

In the case of ethnic and religious minorities, the possibility of such trickster logics becoming dominant are even more evident, as the chains of mediation are even longer, and, thus, their possible abuses greater. This is all the more so as such mediation often progresses through images, and it is very easy to appropriate and abuse images. In such trickster exchanges between the "progressive" center (or quasi-center, itself a mime of the "really" progressive western core) and the "backward" region, two sets of images are particularly attractive and are used in most case studies, including Ireland, where the East-West direction is of course inverted. On the one hand, irresistible images of wealth, health, progress, and development are transmitted to the backward regions, telling the tale of what expects those who fall in the line of progress, giving up every remaining segment of their "non-modern" "identity." Such images can of course be appropriated and retransmitted by local, "alternative," modernizing centers, who try to claim that such progress can only be provided through their own, "communist," "nationalist," or "national-socialist" ways. On the other, images of the "backward" area as hapless, suffering victims are spread in the center, catering for pity, while the same images are also deployed in the marginal areas, mobilizing for a politics of suffering, which can in its due course contaminate the center as well, reducing politics from an effort to promote public good to an impossible effort of eliminating all suffering from the world, alongside the now most influential, Habermas-Rawlsian political philosophy. It is in this sense that the situation of minorities can be taken as a mirror of the situation of the entire marginal region - and not only.

Thus, at one level, the situation of such minorities, reflecting the situation of the entire region, is utterly hopeless. They are chasing a dream that is proved to be a mirage in the center itself, the mirage of a happy and wealthy nation-state - just as those migrants who, in their own desperate situation, are only too happy to believe those tricksters who evoke for them the dream of living in the West, cheating them out of the small but real possessions they actually had. Yet, on the other hand, their very marginality might indeed turn into a value on its own. The articles hint at two possibilities in this regard. First, marginality, for better or worse, can turn into liminality, and this might offer unprecedented connections and insightsas liminal conditions and situations are unpredictable-and may touch 
even upon the highest degree of liminality, in between the divine and the human - though the possibility of trickster interference is also the highest here. Second, on such margins, in certain ways always and necessarily outside the scope of the centers, modes of living different from the mechanized homogenization of the center can also persist. Combined with the previous point, this, after all, offers nonnegligible hope.

\section{CONCLUDING COMMENTS}

Permanent liminality, combined with schismogenic processes, is a paradoxical state that, however, cannot be escaped from those inside, recalling the terminology of "iron cage" or "entrapment" with which Max Weber characterized the modern condition. Reasoning, in particular, is unable to offer any guidance, as it is caught in the web spun from the outside by uprooted, eternally homeless trickster "rationality," which is unsuited to understand political reality that assumes participation and embeddedness in concrete communities. Yet, the rising dominance of trickster reasoning is helped by modern science, which is entrapped in its own - vicious - exterior circularity, based on the void that has evident parallels with the void of the "free and open" public sphere, jointly generating a condition of unreality where, instead of charismatic leaders, trickster politicians are emerging and increasingly dominate, through the "public sphere," the space of modern politics emptied of real presence.

\section{FUNDING}

Work on this special issue received support from the University College Cork Strategic Research Fund and the Centre for Social Sciences, Hungarian Academy of Sciences.

\section{NOTES}

1. For further details, see Agnes Horvath and Arpad Szakolczai, "Political Anthropology," in Stephen Turner and William Outhwaite, eds., Sage Handbook of Political Sociology (London: Sage, forthcoming); Ted C. Lewellen, Political Anthropology: An Introduction, 3rd ed. (Westport, CT: Praeger, 2003); Bjørn Thomassen, "What Kind of Political Anthropology?," International Political Anthropology 1(2): 263-74 (2008); and Bjørn Thomassen and Harald Wydra, eds., Handbook of Political Anthropology (Cheltenham: Edward Elgar, forthcoming). Concerning its application to nationalism and ethnic conflicts, see Thomas Hylland Eriksen, Ethnicity and Nationalism: Anthropological Perspectives (London: Pluto Press, 1993).

2. For details, see Arpad Szakolczai, "Empires: Rise, Decline and Fall," in Bryan S. Turner, ed., Wiley-Blackwell Encyclopaedia of Social Theory (Blackwell: Oxford, forthcoming).

3. Wilhelm Hennis, Max Weber: Essays in Reconstruction (London: Allen \& Unwin, 1988).

4. Max Weber, "Politics as a Vocation," in H. H. Gerth and C. Wright Mills, From Max Weber: Essays in Sociology (London: Routledge, 1948), 128. 
5. Max Weber, The Protestant Ethic and the Spirit of Capitalism (London: Allen \& Unwin, 1976), 182.

6. Max Weber, General Economic History (New Brunswick, NJ: Transaction Books, 1981), 369.

7. For further details, see the various issues of the peer-reviewed journal International Political Anthropology, http://www.politicalanthropology.org.

8. Concerning liminality, see, in particular, Agnes Horvath, Bjørn Thomassen, and Harald Wydra, eds., Breaking Boundaries: Varieties of Liminality (New York: Berghahn Books, 2015); Bjørn Thomassen, Liminality, Change and Transition: Living through the In-Between (Farnham Surrey: Ashgate, 2014). The classic works are Arnold van Gennep, The Rites of Passage (Chicago: University of Chicago Press, 1960; originally published 1909); and Victor Turner, The Ritual Process: Structure and Anti-Structure (New York: De Gruyter, 1969).

9. See Paul Radin, The Trickster: A Study in American Mythology (New York: Schocken, 1972); Agnes Horvath, "Mythology and the Trickster: Interpreting Communism," in Alexander Wöll and Harald Wydra, eds., Democracy and Myth in Russia and Eastern Europe (London: Routledge, 2008); Modernism and Charisma (Basingstoke: Palgrave, 2013); Agnes Horvath and Bjørn Thomassen, "Mimetic Errors in Liminal Schismogenesis: On the Political Anthropology of the Trickster," International Political Anthropology 1(1): 3-24 (2008)

10. See Arpad Szakolczai, Reflexive Historical Sociology (London: Routledge, 2000), 215-26; and Arpad Szakolczai, Permanent Liminality and Modernity (London: Routledge, 2017).

11. See Gregory Bateson, Naven (Stanford: Stanford University Press, 1958); Gregory Bateson, Steps to an Ecology of Mind (New York: Ballantine, 1972); and Horvath and Thomassen, "Mimetic Errors in Liminal Schismogenesis," 3-24.

12. Max Weber, Economy and Society (Berkeley: University of California Press, 1978), 387-93.

13. Thomas Hylland Eriksen, Ethnicity and Nationalism. Anthropological perspectives. (London: Pluto, 2010), 43-69.

14. Rogers Brubaker, Margit Feischmidt, Jon Fox, and Liana Grancea, Nationalist Politics and Everyday Ethnicity in a Transylvanian Town (Princeton: Princeton University Press, 2006).

15. Rogers Brubaker, Nationalism Reframed: Nationhood and the National Question in the New Europe (Cambridge: Cambridge University Press, 1996).

16. See Thomas Hylland Eriksen, "Ethnic Identity, National Identity and Intergroup Conflict: The Significance of Personal Experiences," in Richard D. Ashmore, Lee Jussim, and David Wilder, eds., Social Identity, Intergroup Conflict, and Conflict Reduction (Oxford: Oxford University Press, 2001), 42-70, 46.

17. See Nándor Bárdi, Tény és való: A budapesti kormányzatok és a határon túli magyarság kapcsolattörténete (Pozsony: Kalligram, 2004), 29-30; and Nándor Bárdi, "Different Images of the Future of the Hungarian Communities in Neighbouring Countries, 1989-2012," European Review 21(4): 530-52 (2013).

18. See Eric Voegelin, Anamnesis (Notre Dame: University of Notre Dame Press, 1978).

19. In the Hungarian context, these are the székely-s (Szeklers) or even the Csangos.

20. See József D. Lőrincz, "Ambivalent Discourse in Eastern Europe," Regio: A Review of Studies on Minorities, Politics, and Societies 7(1): 148-71 (2004).

Arpad Szakolczai is Professor of Sociology at University College Cork, Ireland, and previously taught at the European University Institute. His recent books include Comedy and the Public Sphere (2013), Novels and the Sociology of the Contemporary (2016), and Permanent Liminality and Modernity (2017), all by Routledge. His articles and essays appeared among others in the American Journal of Sociology, British Journal of Sociology, British Journal of Political Science, Theory, Culture and Society, and East European Politics and Societies.

Agnes Horvath is a sociologist and political scientist with an interest in an anthropological understanding of modernity. With a $\mathrm{PhD}$ in social and political sciences (European University Institute, Florence, 2000), she taught in Hungary, Italy, and Ireland, was affiliated visiting scholar at Cambridge 
University (2011-2014) and is now Visiting Research Fellow at University College Cork. She is cofounder of International Political Anthropology. Her publications include The Dissolution of Communist Power (Routledge, 1992), Modernism and Charisma (Palgrave, 2013), and Breaking Boundaries: Varieties of Liminality (Berghahn, 2015).

Attila Z. Papp is a sociologist, and he is, since January 2013, Director of the Institute for Minority Studies at the Hungarian Academy of Sciences, Centre for Social Sciences. His research interests include ethnic and minority issues, race and ethnicity, educational research in minority contexts (including the minority aspects of the Programme for International Student Assessment; PISA), and East European Studies. His publications include 21st Century Hungarian Language Survival in Transylvania (Reno, Helena History Press, 2015), Between Minority and Majority: Hungarian and Jewish / Israeli ethnical and cultural experiences in recent centuries (Budapest, Balassi, 2013), Minority Hungarian Communities in the Twentieth Century (Boulder: Atlantic Research and Publications, 2010). 